\title{
Bacterial pathogen 'acutely' involved in otitis media
}

Published online: 10 October 2012

(C) Springer Healthcare 2012

medwireNews: Alloiococcus otitidis can be a dominant bacterial pathogen among indigenous Australian children with acute otitis media with perforation, although its main role appears to be that of a secondary pathogen, preliminary study findings suggest.

The team, led by Robyn Marsh, from Menzies School of Health Research, in Darwin, Australia, note: "In a subset of ear discharge swabs we found high A. otitidis load and relative abundance. The absence of A. otitidis in nasopharyngeal swabs suggests A. otitidis may only have a role in secondary middle ear infection following tympanic membrane perforation.

"Larger longitudinal studies and treatment trials should include paired ear discharge, canal and nasopharyngeal swabs to further test this hypothesis."

The researchers examined paired nasopharyngeal and ear discharge swabs from 27 children who had acute otitis media with perforation. Using quantitative polymerase chain reaction analysis, they found that A. otitidis was present in 11 (37\%) of ear discharge swabs, but in none of the nasopharyngeal swabs.

Culturing A. otitidis-positive swabs revealed that all cultures were positive for other bacteria after 2 days' incubation, with one child positive for more than five bacteria. Furthermore, the minimum inhibitory concentrations determined for A. otitidis isolates suggested that they were resistant to macrolides.

The A. otitidis bacterial load in the positive swabs ranged from $2.2 \times 10^{4}$ to $1.1 \times 10^{8}$ cells $/ \mathrm{swab}$, compared with a total bacterial load of $1.5 \times 10^{4}-8.1 \times 10^{8}$ cells/swab. The relative abundance of A. otitidis ranged from $0.01 \%$ to $34 \%$ of the total bacterial load, at a median of $0.7 \%$.

In six positive swabs, the relative abundance was less than $1 \%$, and it ranged from $2 \%$ to $34 \%$ in the remaining five swabs. These figures were similar to those detected for Haemophilus influenzae, the researchers report in BMC Ear, Nose, and Throat Disorders.

By Liam Davenport, medwireNews Reporter

Reference

BMC Ear Nose Throat Disord 2012, 12: 11 